\section{The Phenomenological Experience of Schizophrenia and Affective Function}

\section{Abstract}

This article proposes that the traditional presumption of affective dysfunction or dysregulation in schizophrenia may not be entirely accurate. Rather, it is argued, the experience of cognitive and perceptual symptoms, coupled with the individual's perception of the challenges associated with their condition may provide a richer and more useful understanding of the emotional experience and expression of persons dealing with schizophrenia. Some of the important implications of this view are discussed in regard to therapy and other interventions.

Keywords: Schizophrenia; Frustration; Cognitive functioning; Perceptual symptoms

Received: September 22, 2017; Accepted: October 05, 2017; Published: October 12,2017

\section{Introduction}

We all know the DSM criteria for schizophrenia, including the positive and negative symptoms that define the condition. Disordered affective function is typically included in descriptions, using terms such as flat, blunt or inappropriate affect [1-3]. Further, when depressive affect is seen, the impression typically shifts to a diagnosis of schizoaffective disorder [2]. Unfortunately, it seems that little attention is given to the phenomenological experience of schizophrenia and how this might relate to affective functioning and expression. In this article, it is hoped that a discussion of the individual experience of schizophrenic symptoms will provide a useful and somewhat different understanding of the emotional world of someone with schizophrenia.

It is useful to think of the common symptomatology of schizophrenia as falling within three main clusters: thinking, perceiving and feeling. Let us begin briefly with the "feeling" dimension, with the intent of returning to this as the effects of the cognitive and perceptual challenges are discussed. Affective functioning is regularly seen as dysregulated. While the reason for this is typically assumed to be a function of schizophrenia itself, it could also be argued that depressed mood, anxiety, anger and frustration, may also be a fairly reasonable and expected response to the experience of cognitive and perceptual symptoms and the life situation and challenges that result. For instance, a patient may begin to chuckle or grin while describing what might be considered a painful emotional experience, such as the chronic illness of a parent. This is generally identified as "inappropriate affect" presuming this affective display is associated with their description of the painful event. However,

\section{Gregory Jurenec* \\ Associate Professor of Clinical Psychology, Wisconsin School of Professional Psychology, USA}

\author{
*Corresponding author: \\ Gregory Jurenec \\ ” jurenec.gregory@wspp.edu \\ Associate Professor of Clinical Psychology, \\ Wisconsin School of Professional \\ Psychology, 9120 W. Hampton Avenue, \\ Milwaukee, WI 53225, USA.
}

Tel: $414-464-9777$

Citation: Jurenec G (2017) The

Phenomenological Experience of Schizophrenia and Affective Function. Acta Psychopathol. Vol. 3 No. S1:67

the nature of the patient's internal stimuli is unknown. Inquiry my reveal that the patient is hearing an auditory hallucination $(\mathrm{AH})$, in which a joke about the examiner is being made. If this is the case, the affect might in fact be considered appropriate, and hence not deregulated. As cognitive and perceptual issues are discussed, an attempt will be made to illustrate how the affective behavior may often (although not always) be appropriate to the patient's unobserved experience.

\section{The Experience or Core Symptoms and Affective Responses}

In the realm of cognitive functioning, a number of deficits relative to the general population have routinely been identified [4]. These include executive function, processing speed, verbal and visual/ spatial learning, verbal and visual/spatial memory, and sustained attention. There have been findings from a longitudinal study done in New Zealand which showed that the rate of development of these cognitive abilities may begin to diverge from nonschizophrenic peers as early as middle school age. Indeed, the author has often noted that adults with schizophrenia often report that they were considered for a diagnosis of attention deficit disorder during childhood.

Consider for a moment the individual's experience of a few of these cognitive challenges. Both processing speed and sustained attention in schizophrenia are sometimes attributed to difficulty 
in screening out irrelevant (or less relevant) stimuli (i.e. one aspect of executive function). In a sense, this can be thought of a "figure-ground" problem. While the reader is reading this article, they must push many stimuli into the background in order to attend to and read this article. Therefore, passing thoughts, recollections this morning's news and weather, physical sensations, street sounds, all are attended to minimally. Many people with schizophrenia (and coincidentally, people with frontal lobe injury) have considerable difficulty doing this. Rather, all of these stimuli may have nearly equal salience. If this is the case, it would take a great deal of effort to attend to a speaker, a book, or even a single train of thought. For the person with schizophrenia, additional internal stimuli might be added to the list, namely $\mathrm{AH}$ and intrusive thoughts. Given the effort required to attend to a single stimulus, even brief attention could be difficult, much less sustained attention. It is easy to see the frustration this may produce in a middle-schooler, leading to possible stigma, lowered expectations, and associated injury to self-concept and self-efficacy. But also consider the experience of feeling that "everything is happening at once". How might this relate to the commonly cited negative symptom of withdrawal and social isolation?

In working with young adults and teens with schizophrenia and their families, the author has often heard parental concerns that the patient will seclude themselves in their darkened room for hours, even days. Common wisdom on psychiatric inpatient units is to "reduce stimulation" when a patent becomes agitated. If a person has difficulty processing information, and screening out less relevant stimuli, it is likely they are easily overwhelmed by the many stimuli in their environment. Therefore, rather than a "negative symptom", withdrawal and isolation may in fact be a reasonably adaptive means of coping with stimulus overload. Further, the experience of emotion is also a stimulus...often a powerful stimulus. If a person is already struggling to manage a flood of stimuli, the experience of anger, sadness, remorse, or even joy may produce an intolerable burden on a person's ability to cope. Therefore, the suppression of affect (which is a common action for non-schizophrenic people) may often be adaptive. Hence, the flat or blunted affect may sometimes reflect a functional adaptive reaction, rather than a "negative symptom" of schizophrenia. This conceptualization would have implications for psychotherapy. Like everyone else, people with schizophrenia experience loss, trauma, and other painful events. Because of the perception of minimal emotional expression, mental health providers may often incorrectly assume that such events have little effect. Instead, the person with schizophrenia may simply have learned that they can be easily overwhelmed if they allow themselves to experience the emotion. Those who practice psychotherapy see this pattern often in their non-schizophrenic patients. Therefore, it may be important to help people with schizophrenia process affect laden issues in therapy. However, the therapist must be mindful to titrate the emotional experience so as to avoid the distress produced by stimulus overload.

Consider another consequence of the cognitive deficits related to schizophrenia: problems with social cognition and theory of mind (TOM) [5]. The concept here is that many people with schizophrenia have difficulty comprehending a perspective other than their own. This difficulty with TOM provides a way of understanding symptoms like ideas of reference: "I'm thinking about me, so those people talking must be talking about me too." In the author's experience, patients often presume others know and accept their thought process and so do not even consider explaining it. They also presume others hear and see what they hear and see. One patient repeatedly chastised this author to "clean out your ears" because he did not hear the voices that the patient heard. Another patient reassured the author that, of course the author could not verbally admit to hearing the voices the patient heard, because the session was being secretly recorded and the author would "get in trouble." These limitations regarding TOM make it very difficult to have satisfying, reciprocal relationships, leading to frequent and often serious misunderstandings. Indeed, many patients with whom the author has worked just "don't get" social relationships. As a result, they often experience painful embarrassment and rejection due to their social blunders. Therefore, many patients are lonely because they have become fearful of seeking social companionship. This is again an example of how cognitive symptoms may lead to behavior and emotional experiences: social estrangement and a level of depression may be more a response to the conditions created by the cognitive symptoms than a part of schizophrenia itself.

Next, let us turn to the individual's experience of positive symptoms, starting with $\mathrm{AH}$. While the various "types" of $\mathrm{AH}$ are described in many sources, from text books to the DSM [2], it is useful consider the functional effect of these experiences. In their paper on source monitoring of $\mathrm{AH}$, Garret and Silva [6] suggest that the person's attribution and perceived function of the $A H$ is important. Imagine the impact of having God, Jesus, Muhammad, or one's deceased parents speak directly to you. The author evaluated a young woman who had previously experienced $\mathrm{AH}$, which had stopped with the use of antipsychotic medication. She said she missed the AH because, "They were my friends." On the other hand, many people with schizophrenia are angered or terrorized by the $\mathrm{AH}$ that they hear. One man at a group home has often fought with staff in his attempt to "escape" because $\mathrm{AH}$ told him that the house was about to explode. Another woman was driven to despair by threats of physical harm by the $\mathrm{AH}$. These are often fully developed emotional expressions in response to stimuli that the patient clearly perceives. Further, if we understand that auditory experience is real to the individual, this emotional response is quite appropriate, and probably should not be considered a sign of affective pathology or emotional dysregulation.

Consider also the effect of the response of a person's social network to $\mathrm{AH}$. When an individual reports $\mathrm{AH}$ to family, friends, and even providers, they can be expected to get the clear message that that this experience is a sign of illness and that the voices they hear are not real. This response serves to estrange the person from the social network and providers, all who could provide valuable support. However, if others deny hearing what one hears with one's own ears, and others view the experience as pathological, a person is very likely to keep further experience private. Therefore, a person is left to struggle alone in their attempt to understand and cope with AH. Again, it is easy to see how this would produce genuine, appropriate feelings of 
abandonment, despair, or even anger.

A similar conceptualization can be applied to the experience of delusions. A former patient explained to the author that he was the "Holy Ghost", had returned from the dead, was "not human", and that he "caused" storms, wars, and even treaties by virtue of his thoughts and even inconsequential actions. However, he readily realized that if he told anyone this (including physicians treating him for GI pain), they would conclude that "I'm crazy". Another patient complained that General Electric had stolen his plans for a sophisticated medical device, but all of the lawsuits he had filed were summarily dismissed. He was disconsolate because "no one believes me." Imagine what it must be like to "know" something, as do these individuals, which no one else believes. There have been many movies that play on this theme in order to produce feelings of fear, anger, despair, and self-doubt in the audience. Again, if one can appreciate the patient's belief in such delusions as "fact", the subsequent emotional reactions can again be seen as a very appropriate affective response.

Delusions and emotions can also be considered from another perspective. In some cases, delusions may serve a compensatory function. The clearest example may be grandiose delusions. The author worked with a chronically very psychotic man who resided on a locked inpatient unit. His father was recently diagnosed with terminal brain cancer. While the patient had long believed that he was an independently wealthy owner of a large company, he developed the new delusion that he had purchased a new car and home for his parents. It appears that he compensated for his inability to be with or help his dying father by believing that he had bought his parents everything they might need. Similarly, the author worked with another chronically mentally ill man who had a learning disability. While he had not graduated high school, most of his family was highly educated and economically successful. He believed that he was an influential talent agent (and that he "discovered" Michael Jackson) and that he was appointed by President Nixon to be the Chief Justice of the Supreme Court. After many rational challenges to these beliefs, he one day responded in anger, "If you take this away from me, then what do I have?" In each of these cases, the patient's delusion provided a way of coping with realistic, painful emotions.

Lastly, let us look at the feelings that might be associated with a realistic appraisal of one's life situation. This author and others have argued that the approach to treatment of schizophrenia is far behind the more enlightened approach used in other countries [7-9]. The result of the reliance on a medical model of treatment, and almost exclusive reliance on the use of antipsychotic medication, often has a significant impact on a person's perception of their attainable future. It is often communicated to patients that the prospect for a "normal" life has become less likely following a diagnosis of schizophrenia. For example, a 26 year old woman seen by the author expressed her unhappiness that her court-ordered treatment over the last 10 years effectively prevented her from "having a life". Like anyone her age, she wants to have a boyfriend, hold a job, have a home, get married, and have a family. But, she feels thwarted in her ability to pursue those goals. This is due in part to the limitations she feels are placed on her, but also due to some awareness that her condition will make some of these goals difficult to achieve.
How must this feel? It is not surprising that she has episodes of anger and frustration at the group home in which she resides, as well as periods of what staff describes as a low level depression and hopelessness. Similarly, the author works with a chronically psychotic man who is nearing 60. At points, he has discussed his desire to have a wife and children, hold a job, and have a house. However, at times he is keenly aware that he has never been able to do this, and it is highly unlikely he ever will. It would seem that these realistic appraisals would lead to some level of depression in people with schizophrenia, just as they would for anyone else.

\section{Implications for Therapy}

These conceptualizations regarding the experience of symptoms and affective responses have important implications for working with people who have schizophrenia. But first, consider a universal model of treatment proposed by Bruce Wampold [10]. He proposes treatment is akin to a "ritual", and argues that for most any treatment to be effective (somatic or psychological) several ingredients have to be present:

1. The subject must believe that you care and understand them.

2. And that you CAN help them.

3. That you given them an alternative, more adaptive explanation for their problem, which the patient is willing to adopt. Their willingness to accept this depends, in part, on numbers 1 and 2 .

4. You carry out interventions that are consistent with that model.

This model can be seen in conventional psychotherapy, but also in work with patients dealing with schizophrenia. Key to the present discussion is the communication of caring and the understanding of the patient's experience. It is argued here that only by understanding and appreciating the patient's experience can you frame interventions that will be helpful $[11,12]$. For instance, if you do not understand the patient's interpretation of their $\mathrm{AH}$, you cannot be effective in helping them cope. If you respond to their admission of $\mathrm{AH}$ by denying the reality of their experience, this will likely doom your ability to help. Such a statement devalues the patient's experience, and they will no longer be willing to share important information with you. Further, without understanding the nature of the $A H$ is essential to your effectiveness. For instance, one of the author's patients shared that a particular voice regularly promised him that he would be "beamed up" to a spaceship that would take him to Mars that day. But, he was very frustrated that this never happened. Rather than arguing about the reality of the $\mathrm{AH}$, the author questioned why he would listen to a voice that was consistently untruthful. The patient was thoughtful, concluded that the voice was lying to him, and decided he would try to disregard this voice in the future.

An understanding of the nature of a patient's $\mathrm{AH}$ can also help in dealing with the patient's behavioral response to the $\mathrm{AH}$. For instance, if a patient is becoming angered by the insults directed at him by voices, you can work with the patient to refute or discredit the insults, much as you might do if these were from an actual person. If a patient is frightened by the threats of harm 
from their $\mathrm{AH}$, you can work with the patient on ways to protect themselves from possible harm by the $A H$.

In a similar fashion, an understanding of a patient's delusional system is invaluable to developing effective interventions. It should be emphasized that, seeking an understanding of the delusion is not the same as endorsing or confirming the delusion. In contrast, by disputing the veracity of the delusion, the provider again risks the loss of the patient's trust and confidence. Conversely, attempts to prove the disprove the delusion are nearly always unsuccessful. Indeed, delusions are not subject to reason and logic. (If they were, they would not be delusions!) However, this understanding can offer several therapeutic opportunities. Again, there must be an appreciation by the therapist that the delusion is a reality for the patient. This is a reality that produces feelings and motivates behavior.

One important therapeutic opportunity is to help the patient deal with their emotional response to the belief. For example, the author worked with a young man who believed that his wife and children had moved away, without explanation. He also believed that they were now trying to come back, but could not find him. While he in fact was never married and there were no real children, his grief and distress were quite real. Therefore, it proved effective to work with him on his grief. (It is possible that he was actually grieving that he had never been able to marry and have children.) Similarly, it was helpful to help another patient deal with the anger and frustration of the theft of his patent after all of his legal efforts failed.

Another opportunity is to consider the function the delusion may serve, and address that function in therapy, rather than the delusion itself. For instance, one patient would launch into delusions about his importance (i.e. supernatural powers, an agent for the United Nations, and head of the Mafia) when he felt minimized or disrespected by staff at his group home. The focus of therapy then became coping with feelings of being disrespected, how he might respond, and what he could do to build self-esteem.

\section{References}

1 Torrey EF (2013) Surviving schizophrenia: a family manual (6 $6^{\text {th }}$ Edn) Harper Perennial, New York.

2 American Psychiatric Association (2013) (6 ${ }^{\text {th }}$ Edn), Diagnostic and statistical manual of mental disorders. American psychiatric Publishing, Washington DC, USA.

3 Kring AM, Elis O (2013) Emotion deficits in people with schizophrenia. Annu Rev Clin Psychol 9: 409-433.

4 Fioravanti M, Carlone O, Vitale B, Cinti EC, Clare L (2005) A meta-analysis of cognitive deficits in adults with a diagnosis of schizophrenia. Neuropsychol Rev 15: 73-95.

5 Bechi $M$, Bosia $M$, Spangaro $M$, Buonocore $M$, Cocchi $F$, et al. (2015) Combined social cognitive and neurocognitive rehabilitation strategies in schizophrenia: neuropsychological and psychopathological influences on theory of mind improvement. Psychol Med 45: 3147-3157.
A third opportunity is to address problematic behavior that stems from the delusion by working within the delusional system to change the behavior. For instance, a young woman at a group home refused to sleep at night because she believed that God had ordered her to stay awake to protect the universe. It was suggested to her that she may not be a very effective protector when she is sleep deprived. So, she might ask God if she could be allowed to sleep at night so she can do the best job of protecting the universe. She thought this was reasonable, and decided to ask God this question. She was pleased that God agreed and told her that she should sleep at night.

\section{Conclusion}

This article argues that the traditional understanding of schizophrenia may incorrectly construe the affective experience of persons with schizophrenia. The "flat", "blunt" or "constricted" affect often cited may in fact be an adaptive, protective means of coping with stimulus overload. The perception of "inappropriate" affect may actually reflect a misunderstanding of the actual stimuli to which the patient is responding. Further, an understanding of the actual individual experience of cognitive and perceptual symptoms, along with the individual's realistic appraisal of their life situation may reveal the appropriateness of the feelings of depression, hopelessness, anger, frustration and despair. Therefore, it may not be helpful to view these emotional expression as part of and "affective disorder" but rather as reasonably normal and expected reactions to the events that the person with schizophrenia experiences. More broadly, our ability to effectively help our patients depends largely on the extent to which we are able to see the world through the eyes of our patients. Because such an understanding is not widespread, persons with schizophrenia often feel estranged from their support system and providers. Therefore, this understanding is vital to providing effective help to people who dealing with schizophrenia.

6 Garret M, Silva R (2003) Auditory hallucinations, source monitoring and the belief that voices are real. Schizophr Bull 29: 445-457.

7 Mosher LR, Hendrix V (2004) Soteria: through madness to deliverance. IN: Xlibris, Bloomington, Indiana.

8 Bola JR, Mosher LR (2003) Treatment of acute psychosis without neuroleptics: two-year outcomes from the Soteria project. J Nerv Ment Dis 191: 219-229.

9 Calton T, Spandler H (2009) Minimal-medication approaches to treating schizophrenia. Adv Psychiatr Treat 15: 209-217.

10 Wampold B (2007) Psychotherapy: the humanistic and effective treatment. Am Psychol 62: 857-873.

11 Jurenec GS (2011) Living with schizophrenia: a brief guide to understanding and coping for patients, families and providers. Xlibris Corporation.

12 Meier MH, Caspi A, Reichenback A, Keefe R, Fisher HL, et al. (2013) Neuropsychological decline in schizophrenia from the premorbid to the post onset period: evidence from a population-representative longitudinal study. Am J Psychiatry 171: 91-101. 